\title{
Editorial
}

\section{Zika Virus - An Upcoming Challenge?}

Md. Rezwanur Rahman

Professor of Biochemistry

Delta Medical College, Dhaka, Bangladesh

Zika virus is a flavivirus in the family Flaviviridae, that was first isolated in 1947 from a sentinel rhesus monkey in a Ugandan forest, with the first human cases identified 5 years later in Nigeria. ${ }^{1,2}$ After remaining in relative obscurity for nearly 60 years; it came as a great surprise when the 2007 outbreak of Zika virus on several islands in the State of Yap, Federated States of Micronesia, resulted in an estimated 5000 infections among the total population of $6700 .^{3}$ Subsequently, an outbreak in French Polynesia in 2013 and 2014 is estimated to have involved 32,000 persons and this time cases of Guillain-Barré syndrome were also noted. ${ }^{4}$ Subsequent outbreaks occurred on other Pacific islands in the next two years. ${ }^{5}$ Then, within the span of just 1 year, Zika virus was introduced into Brazil from the Pacific Islands, spread rapidly to at least 33 countries and territories in the Americas and by March 2016, a total of 51,473 suspected cases of Zika virus had been reported in Brazil. By September 2015, investigators in Brazil noted an increase in the number of infants born with microcephaly in the same areas in which Zika virus was first reported, and by mid-February 2016, more than 4300 cases of microcephaly had been recorded. ${ }^{6,7}$ It became the first major infectious disease linked to human birth defects to be discovered in more than half a century and created such global alarm that the World Health Organization (WHO) would declare a Public Health Emergency of International Concern on February $2016 .^{7}$

\section{Zika Virus Transmission}

Mosquito-borne Transmission

Humans become infected with Zika virus mainly through the bites of several species of aedes mosquitoes, including Aedes aegypti and presumably Aedes albopictus. ${ }^{1,2}$

\section{Non mosquito Transmission}

Substantial evidence now indicates that Zika virus can be transmitted from the mother to the fetus during pregnancy. Zika virus RNA and viral antigen have been identified in the amniotic fluid of mothers whose fetuses had cerebral abnormalities detected by ultrasonography, in the brain tissue and placentas of children who were born with microcephaly, as well as in tissues from miscarriages. ${ }^{1}$

Sexual transmission to partners of returning male travelers who acquired Zika virus infection abroad has been reported. Replicative viral particles, as well as viral RNA - often in high copy numbers have been identified in sperm, and viral RNA has been detected up to 62 days after the onset of symptoms. Although the transmission of Zika virus through a blood transfusion has yet to be reported, it is likely to occur. ${ }^{1}$

\section{Diagnosis}

The mainstays of routine diagnosis of Zika virus infection are the detection of viral nucleic acid by RT-PCR and the detection of IgM antibodies by IgM-capture enzyme-linked immunosorbent assay 
(MAC-ELISA). Reliable testing regimens for the diagnosis of prenatal and antenatal Zika virus infection have not been established. Amniotic fluid has tested positive by RT-PCR in instances of congenital Zika virus infection; however, the sensitivity of RT-PCR in this context is unknown. ${ }^{8}$

\section{Treatment, Prevention, and Control}

As with the other mosquito-borne flaviviruses, treatment for uncomplicated Zika virus infection focuses on symptoms. No Zika virus vaccine exists; thus, prevention and control measures depend on avoiding mosquito bites, reducing sexual transmission, and controlling the mosquito vector. Potentially effective methods of prevention that are focused on reducing infections among pregnant women include avoiding unnecessary travel to areas of ongoing Zika virus transmission, avoiding unprotected sexual contact with partners who are at risk for Zika virus infection, and using mosquito repellent, permethrin treatment for clothing, bed nets, window screens, and air conditioning. 1

The most effective vector control relies on an integrated approach that involves elimination of aedes mosquito breeding sites, application of larvicides, and application of insecticides to kill adult mosquitoes. However, each of these approaches has substantial limitations. Communities are often mobilized to reduce the breeding sites, but this strategy often fails, in part because of inconsistent participation among households and the presence of cryptic breeding sites in modern urban settings. ${ }^{1}$

\section{Zika virus in Bangladesh}

As the epidemic expands its range, increasing numbers of travellers are transporting Zika virus to distant regions across the world and countries across Africa and the Asia-Pacific region are becoming increasingly susceptible to the importation and possible local spread of the virus. An estimated 2.6 billion people live in areas of Africa and the Asia-Pacific region where the presence of competent mosquito vectors and suitable climatic conditions could support local transmission of Zika virus. $^{2}$ The Lancet Infectious Diseases published a study where the authors have speculated that Bangladesh along with India, Pakistan, China, Vietnam and Thailand could be particularly vulnerable to Zika outbreak as these countries have mosquitoes capable of transmitting Zika virus, climate conditions conducive to local spread, and their limited health resources $.9,10$

After the declaration of Zika virus infection as a public health emergency by the World Health Organization (WHO), the WHO South-East Asian region, of which Bangladesh is a member, has also been urged to "strengthen surveillance and take preventive measures" against the disease. ${ }^{11}$ Bangladesh officially confirmed its first case of Zika virus infection on March 2016 in an old sample of blood from a 67 years old man living in Chittagong who has never been abroad. ${ }^{12}$ In October 2016 Centers for Disease Control and Prevention stated that $\mathrm{Zika}$ is endemic in Bangladesh but the risk to travelers is low. ${ }^{13}$ There is also a ray of hope that as our people are already exposed to aedes mosquito bites there may be some sort of immunity developed which makes the disease intensity low.

As there is no specific treatment and currently no vaccine is available, the main approach to combat Zika and to protect ourselves is prevention and the measures mentioned earlier are also very much applicable for us. Strategic use of available health and human resources is essential to prevent or mitigate the health, economic, and social consequences of Zika virus, especially in a resource-limited country like ours. The WHO Vector Control Advisory Group (VCAG) also 
recommended that well implemented vector control programmes using existing tools and strategies are effective in reducing the transmission of Aedes-borne diseases, including Zika virus. These tools should be promoted and used to control the Zika virus. They include: (i) targeted residual spraying; (ii) space spraying; (iii) larval control; and (iv) personal protection measures. ${ }^{14}$

Delta Med Col J. Jan 2017;5(1):1 - 3

\section{References}

1. Petersen LR, Jamieson DJ, Powers AM, Honein, MA. Zika Virus. N Engl J Med. 2016;374:1552-63.

2. Bogoch II, Brady OJ, Kraemer MUG, German M, Creatore MI, Brent S, et al. Potential for Zika Virus Introduction and Transmission in Resource-Limited Countries in Africa and the Asia-Pacific Region: A Modelling Study. Lancet Infectious Diseases. 2016;16(11):1237-45.

3. Duffy MR, Chen T-H, Hancock WT, Powers AM, Kool JL, Lanciotti RS, et al. Zika Virus Outbreak on Yap Island, Federated States of Micronesia. N Engl J Med 2009;360:2536-2543

4. Rapid Risk Assessment: Zika Virus Infection Outbreak, French Polynesia. Stockholm: European Centre for Disease Prevention and Control [Internet]. 2014 Feb 14 (cited 2017 Jan 25). Available from: http://www.ecdc.europa.eu/en/publications/Publicati ons/Zika-virus-French-Polynesia-rapid-risk-assessm ent.pdf.

5. Gulland A. Zika Virus is a Global Public Health Emergency, Declares WHO. BMJ. 2016;352:1657i657.
6. Tognarelli J, Ulloa S, Villagra E, Lagos J, Aguayo C, Fasce R, et al. A Report on the Outbreak of Zika Virus on Easter Island, South Pacific, 2014. Arch Virol. 2016;161:665-68.

7. Zika Virus Spreads to New Areas - Region of the Americas, May 2015-January 2016. MMWR Morb Mortal Wkly Rep. 2016;65:55-58.

8. Bearcroft WG. Zika Virus Infection Experimentally Induced in a Human Volunteer. Trans R Soc Trop Med Hyg 1956;50:442-48.

9. India, China, Pakistan, Bangladesh Vulnerable to Zika Virus: Study. The Indian Express. 2016 Sep 2(cited 2017 Jan 25). Available from: http:// indianexpress.com/article/lifestyle/health/india-chin a-pakistan-bangladesh-vulnerable-to-zika-virus-stud y-3009841.

10. Bangladesh 'Susceptible' to Zika Outbreak. 2016 Sep 2 (cited 2017 Jan 25). Available from: http://www.thefinancialexpress-bd.com/2016/09/02/ 44330/Bangladesh-'susceptible'-to-Zika-outbreak.

11. bdnews24.com [Internet]. Hasib NI. Bangladesh Gears Up Zika Virus Prevention Plan after WHO Emergency Call. 2016 feb 2 (cited 2017 Jan 25). Available from: http://bdnews24.com/health/2016 /02/02/bangladesh-gears-up-zika-virus-prevention-p lan-after-who-emergency-call.

12. Bangladesh Officially Confirms Presence of Zika Virus. 2016 Oct 8 (cited 2017 Jan 25). Available from: http://amardesh24.com/index.php/details/ nationalnews/2Saturday, 08 Oct 2016.

13. Centers for Disease Control and Prevention [Internet]. Health Information for Travelers to Bangladesh. Traveler View. 2016 Oct 20 (cited 2017 Jan 25). Available from: https://wwwnc.cdc. gov/travel/destinations/traveler/none/bangladesh.

14. WHO [Internet]. Mosquito (Vector) Control Emergency Response and Preparedness for Zika Virus. 2016 March 18 (cited 2017 Jan 25). Available from: http://www.who.int/neglected_diseases/news/ mosquito_vector_control_response/en/. 